\title{
Effect of Pen Floor Material on the Behavior of Hanwoo Cattle
}

\section{Yang, Ka Young}

Laboratory of Animal Production and Ecology, Kuju Agricultural Research Center, Faculty of Agriculture, Kyushu University | Division of Animal Resource Science, College of Animal Life Sciences, Kangwon National University

\section{Park, Kyu-Hyun}

Laboratory of Animal Production and Ecology, Kuju Agricultural Research Center, Faculty of Agriculture, Kyushu University | Division of Animal Resource Science, College of Animal Life Sciences, Kangwon National University

Ha, Jae Jung

Laboratory of Animal Production and Ecology, Kuju Agricultural Research Center, Faculty of Agriculture, Kyushu University | Gyeonsangbuk-Do Livestock Research Institute

\section{Gotoh, Takafumi}

Laboratory of Animal Production and Ecology, Kuju Agricultural Research Center, Faculty of Agriculture, Kyushu University

他

https://doi.org/10.5109/1800842

出版情報: 九州大学大学院農学研究院紀要. 62 (1)，pp.99-103，2017-02-24. Faculty of Agriculture， Kyushu University

バージョン :

権利関係 : 


\title{
Effect of Pen Floor Material on the Behavior of Hanwoo Cattle
}

\author{
Ka Young YANG ${ }^{1}$, Kyu-Hyun PARK ${ }^{1}$, Jae Jung HA ${ }^{2}$, Takafumi GOTOH \\ and Young Han SONG ${ }^{1 *}$
}

\author{
Laboratory of Animal Production and Ecology, Kuju Agricultural Research Center, \\ Faculty of Agriculture, Kyushu University, Oita 878-020, Japan \\ (Received October 31, 2016 and accepted November 4, 2016)
}

\begin{abstract}
This study was conducted to investigate the effect of three types of pen floor litter materials (sawdust, wood shavings and rice husk) on the behavior of growing Hanwoo calves. Twelve Hanwoo calves (121.4 \pm $19.9 \mathrm{~kg}$ ) were housed in an open barn for 6 months. Two heifers and two steers were housed in a pen on each litter treatment and two replications per each treatment were conducted. Temperature, humidity and cow behavior were observed after a 15 day adaptation period. Average daily gain was higher in winter and spring than in summer $(\mathrm{p}<0.05)$. Feeding behavior was significantly shorter in summer compared with other seasons $(p<0.05)$. Lying behavior was significantly longer in cows housed on the sawdust treatment during summer $(\mathrm{p}<0.05)$. The frequency of self-licking and social licking behavior was higher in the spring $(p<0.05)$ compared with other seasons. During winter, body and tail rubbing behaviors increased $(p<0.05)$. With consideration of cattle welfare and farm budget, sawdust or wood shavings litter during spring and summer and rice husk litter during winter were regarded as the most beneficial, for optimum lying and licking behavior of Hanwoo beef cattle. Rice husk is usually cheaper during harvest compared with other seasons because of its abundance.
\end{abstract}

Key words: Litter types, Behavior, Hanwoo cattle, Seasonal

\section{INTRODUCTION}

At 6 to 12 months of age, Hanwoo cattle, has a basic body type that is adequate to tolerate the long-term fattening stage. Consequently, the growing stage is important for rearing management compared with the subsequent fattening stage (Hanwoo Research, 2005). Cattle spend most of their life in pens. Bedding material used on the pen floor to improve the environment within the pen, such as rice straw, is commonly placed on concrete slatted floors. Using rice straw as bedding controls humidity and temperature and therefore provides comfort and, reduces stress (Phillips et al., 2000). Consequently, the material used on the pen floor is one welfare indices for cows and needs to comply with some essential standards. Litter material should be absorbent, as dust-free as possible, and the animal should feel comfortable (Irps, 1987). Previous research has indicated that litter material can affect animal behavior. Fregonesi et al. (2007) reported that cows laid down for longer on straw litter with a low moisture content compared with a high moisture content.

Animals generally expressed maintenance behavior (e.g. feeding, drinking water, rest and, grooming) and social behavior (e.g. licking and aggressiveness) (Martin and Bateson, 2007). Resting behavior has been defined as lying on one side (Song, 1996). Mimura (1997) reported that as maintenance behavior for their body or skin care, ruminants lay on one side and groomed them-

\footnotetext{
1 Division of Animal Resource Science, College of Animal Life Sciences, Kangwon National University, the Republic of Korea

2 Gyeonsangbuk-Do Livestock Research Institute, Muk-ri 275, Yeongju Gyeonsngbuk-Do 750-871, the Republic of Korea

* Corresponding author (E-mail: yhsong@kangwon.ac.kr)
}

selves for 12 hours a day. Spiger et al. (1972) reported that the grooming behavior of animals was effective to remove mud, rice husk, parasites and insects on the skin and to reduce the risk of diseases.

Research has demonstrated that climatic environment can affect livestock productivity (Nonaka et al., 2008; Havlin and Robinson, 2015). Rearing environment was one factor affecting feed efficiency, livestock productivity, growth and breeding (Kim and Jung, 2004; Metz et al., 1986). Additionally, a previous study has shown quality and quantity of milk was associated with dairy cow hygiene. Conversely, beef cattle productivity was associated with a comfortable environment (Rook and Thomas et al, 1983). The temperature-humidity index is commonly used to assess thermal comfort for cattle (Legrand et al., 2009).

The aim of this study was to investigate the effect of pen litter material on Hanwoo cattle behavior.

\section{MATERIALS AND METHODS}

\section{Animals Housing}

This study was conducted at the Kangwon National University farm. Sawdust, wood shavings and rice husks were placed separately, $10 \mathrm{~cm}$ deep, as litter in barns. Cows were managed in compliance with the Korean Hanwoo feeding management guidelines (NIAS: National Institute of Animal Science, 2007). Cows were fed twice a day (0800 and $1700 \mathrm{~h}$ ). Water and mineral blocks were available ad libitum. The concentrate and rice straw were collected for analysis at the beginning of the experiment and subsequently every 2 months. Feed intake was measured every 3 days. Rice straw was collected from five random locations in the pen (Figure 1) at the beginning of the experiment and every 15 days and ana- 


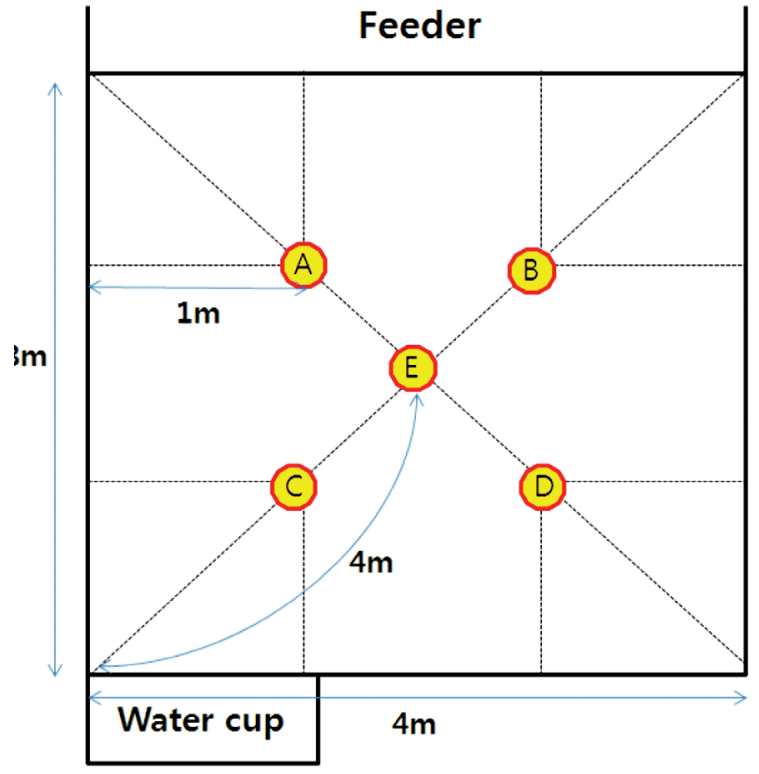

Fig. 1. Location of bedding sampling sites in each pen (A, B, C, D and E).

lyzed for moisture content according to the method described by AOAC (1995).

\section{Cows and experimental design}

Dried rice straw, annual ryegrass straw (Italian ryegrass straw) and Klein grass hay were used as forage feed. Restricted feeding was performed using a mixture of concentrates and forage, at a ratio of 6 (concentrate) : 4 (forage), according to the total digestible nutrients
(TDN) required for maintaining a mature cow, based on the Korean feeding standard from the National Institute of Animal Science (NIAS, 2007). Twelve Hanwoo calves (body weight $=121.4 \pm 19.9 \mathrm{~kg}$ ) were reared in an open barn for 6 months. Four cows were housed in a pen with each type of litter. After a 15-day adaptation period, measurements commenced, between February and August, 2015.

\section{Observation of behavior}

Six digital cameras (IR LED Camera; APD-7070 V; Sony; Japan) were installed facing each pen at a distance of $1.5 \mathrm{~m}$, housed in a cabinet near the barn entrance. All the behaviors of the cows were recorded between 0700 and 1900 on each day of the experiment; however, only data from clear days were selected for the analysis. Weather such as rain could cause background noise, disrupting the sound quality and could frighten the cows, reducing the quality of data.

Each cow's behavior in the pens was traced. These data were then pooled and used to analyze four cows' behavior during each treatment. Video footage was analyzed for frequency and duration of different behaviors on a behavior checklist, which included feeding, standing, walking and lying. Frequency of self-licking, social licking, body rubbing and tail rubbing was also recorded (Martin and Bateson, 2007).

\section{Temperature and humidity}

Temperature and humidity were measured on a data logger (Testo 174T data logger, 1-channel; Germany) that recorded temperatures every 1 hour. The data logger was placed in the center of the barn to record daily

Table 1. Temperature and humidity at Kangwon National University Farm during the experiment

\begin{tabular}{lrcc}
\hline Month & Temperature $\left({ }^{\circ} \mathrm{C}\right)$ & Relative Humidity $(\%)$ & $\mathrm{THI}^{1}$ \\
\hline February & $-2.9 \pm 4.0$ & $52.1 \pm 18.2$ & $33.5 \pm 2.1$ \\
March & $5.3 \pm 2.3$ & $46.8 \pm 14.4$ & $44.4 \pm 0.5$ \\
April & $16.4 \pm 0.5$ & $42.5 \pm 0.1$ & $57.1 \pm 0.6$ \\
May & $19.7 \pm 3.3$ & $56.4 \pm 0.0$ & $63.4 \pm 3.9$ \\
Jun & $23.2 \pm 0.9$ & $60.2 \pm 0.0$ & $69.0 \pm 0.4$ \\
July & $26.2 \pm 0.9$ & $65.4 \pm 4.5$ & $74.1 \pm 2.0$ \\
August & $28.5 \pm 1.1$ & $68.7 \pm 1.0$ & $77.3 \pm 0.2$ \\
\hline
\end{tabular}

1) Temperature humidity index (Mader et al., 2006): $(0.8 \times \mathrm{T})+[(\mathrm{RH} / 100) \times(\mathrm{T}-14.4)]+46.4$.

Table 2. Data of 10-year weather in Chun-cheon city (2002-2012)

\begin{tabular}{|c|c|c|c|}
\hline & $\mathrm{Tdb}^{1)}$ & $\mathrm{RH}^{2)}$ & $\mathrm{THI}^{3)}$ \\
\hline Winter & $2.2 \pm 3.04$ & $59.3 \pm 6.27$ & $40.9 \pm 6.22$ \\
\hline Spring & $17.1 \pm 4.50$ & $63.4 \pm 5.95$ & $62.0 \pm 7.54$ \\
\hline Summer & $24.7 \pm 0.95$ & $79.3 \pm 3.32$ & $74.4 \pm 1.54$ \\
\hline
\end{tabular}


minimum and maximum temperatures and humidity. Temperature and humidity were used to calculate temperature humidity index (Table 1). At this time, winter, spring, and summer were categorized in the THI range of Table 2 .

Temperature and humidity index was calculated using the equation reported by Mader et al. (2006) below:

$$
\begin{aligned}
& \text { THI }=(0.8 \times \mathrm{T})+[(\mathrm{RH} / 100) \times(\mathrm{T}-14.4)]+46.4 \\
& \mathrm{THI}: \text { temperature-humidity index } \\
& \mathrm{T}: \text { air temperature }\left({ }^{\circ} \mathrm{C}\right) \\
& \mathrm{RH}: \text { relative humidity }(\%) .
\end{aligned}
$$

\section{Data selection and statistical analysis}

For this study, only data collected on dry days were selected and used in the analysis. A factorial analysis in a random-parcel experimental design was applied, to determine the effects season and litter type on body weight performance and behavior of growing Hanwoo cattle. Statistical analysis was conducted using the general linear model (GLM) with a randomized complete block design. The season and type of litter material were also included as an interaction effect, using the PROC MIXED function of SAS (version 9.1, SAS Institute,: USA, 2003).

\section{RESULTS AND DISCUSSION}

Average daily gain (ADG) was higher in cattle housed on the wood shavings litter compared with the other litter types, but there was no statistical difference between types of litter materials ( $>>0.05)$. Gottardo et al. (2003) also reported ADG was not affected by different types of litter material. However, there were seasonal differences in ADG. Higher ADG was observed during winter and spring $(p<0.05)$ compared with summer (Table 4). There was no interaction between season and type of litter materials. ADG increased more in winter and spring than in summer $(p<0.01)$.

Feeding behavior was significantly shorter in summer compared with other seasons $(\mathrm{p}<0.05)$ (Table 3). Lying behavior was significantly longer $(p<0.05)$ in cattle housed on the sawdust litter during summer compared with other seasons. Gygax et al. (2007) reported that lying behavior increased in pens with straw litter compared with fully slatted floors. Song et al. (2007) showed that cattle lay down for significantly longer during summer than in autumn and winter. It is possible that rice husk litter has a lower moisture content than sawdust and wood shavings. Fregonesi et al. (2007) and Reich et al. (2010) reported that cows lay down longer on litter with a lower moisture content. Lee (2014) reported that sawdust demonstrated the best water absorption ability. Rice husk absorbed less water than sawdust even though it was the most widely used litter in Korea. In our study, cows lay down for the shortest time on rice husk bedding (Table 3 ).

Time budget of walking behavior was higher in the spring compared with other seasons and was the highest on sawdust and the lowest on rice husk litter ( $p>0.05$ ) (Table 4). The interaction between season and bedding materials was not significant $(p>0.05)$. These results were consistent with a study by Grossi et al. (2005) that demonstrated cattle were more stressed with low and high temperatures, which affected by hormone levels, body temperature control and excretion behavior. In a further study, it was demonstrated that the longer cows lay down, the more comfortable cows felt (Haley et al.,

Table 3. Effect of pen floor material type and season on behavior in 12 growing Hanwoo cattle

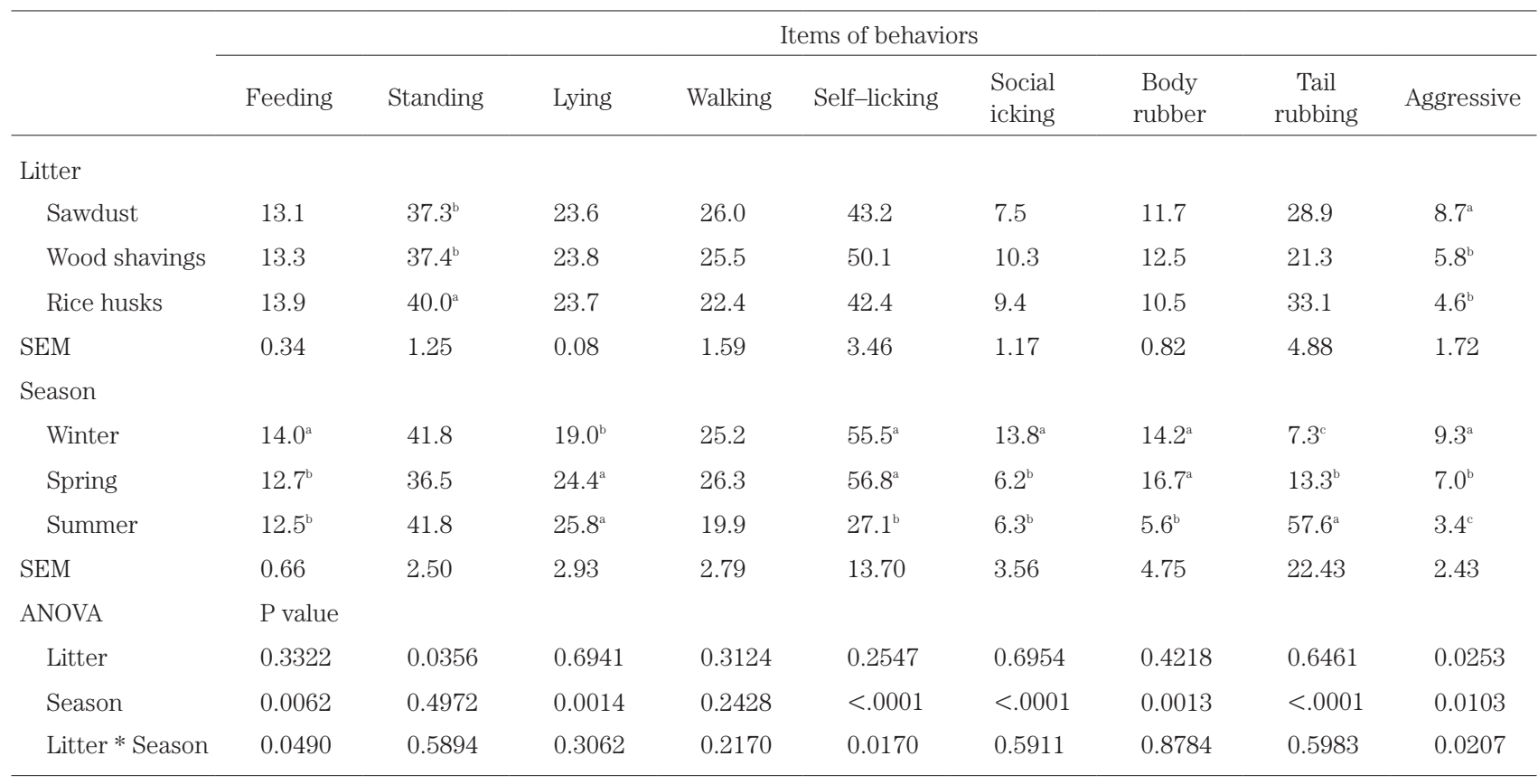

SEM : Standard error of mean.

${ }^{a-c}$ Means with different superscripts in the same column differ significantly $(p<0.05)$ 
Table 4. Effect of litter type on growth performance and feed intake in growing Hanwoo cattle

\begin{tabular}{|c|c|c|c|c|}
\hline & Initial body weight(kg) & Final body weight $(\mathrm{kg})$ & ADG, kg/day & FI (DM), kg/day \\
\hline \multicolumn{5}{|l|}{ Litter } \\
\hline Sawdust & $152.5 \pm 14.85^{\mathrm{a}}$ & $287.7 \pm 11.67^{\mathrm{a}}$ & $0.61 \pm 0.05$ & $4.86 \pm 0.64$ \\
\hline Wood shavings & $120.0 \pm 21.21^{\mathrm{ab}}$ & $259.2 \pm 33.59^{\mathrm{ab}}$ & $0.65 \pm 0.06$ & $4.86 \pm 0.64$ \\
\hline Rice husks & $92.75 \pm 3.89^{b}$ & $218.7 \pm 15.91^{b}$ & $0.59 \pm 0.06$ & $4.86 \pm 0.64$ \\
\hline SEM & 24.42 & 28.31 & 0.02 & - \\
\hline \multicolumn{5}{|l|}{ Season } \\
\hline Winter & $121.3 \pm 5.27^{\circ}$ & $132.5 \pm 2.55^{\circ}$ & $0.75 \pm 0.02^{\mathrm{a}}$ & $4.53 \pm 0.00$ \\
\hline Spring & $152.04 \pm 1.83^{\mathrm{b}}$ & $196.7 \pm 4.49^{\mathrm{b}}$ & $0.75 \pm 0.07^{\mathrm{a}}$ & $4.75 \pm 0.00$ \\
\hline Summer & $221.8 \pm 6.92^{\mathrm{a}}$ & $250.6 \pm 7.11^{\mathrm{a}}$ & $0.51 \pm 0.01^{\mathrm{b}}$ & $5.42 \pm 0.00$ \\
\hline SEM & 42.04 & 48.27 & 0.11 & - \\
\hline \multicolumn{5}{|l|}{ ANOVA } \\
\hline Litter & 0.5778 & 0.4870 & 0.4681 & - \\
\hline Season & $<.0001$ & $<.0001$ & $<.0001$ & - \\
\hline Litter * Season & 0.9798 & 0.9609 & 0.7931 & - \\
\hline
\end{tabular}

SEM: standard error of means.

FI: Feed intake

ADG: average daily gain; DMI: dry matter intake.

${ }^{a-c}$ Means with different superscripts in the same row are significantly different $(p<0.05)$

2001).

Self-licking and social licking frequency was significantly higher in spring $(\mathrm{p}<0.05)$ compared with other season, as shown in Table 3. In addition, ADG was higher in spring and winter compared with summer $(\mathrm{p}<0.05)$. Conversely, Ishi (1986) reported that licking frequency and weight gain of cattle increased.

Body rubbing helps to maintain healthy pelage in areas that cannot be reached through self-grooming (Sato et al., 1991). Body rubbing was performed on areas where the cow's feet could not reach and tended to be higher in winter and spring compared with summer $(p<0.05)$ (Table 3). However, tail rubbing was the highest in the summer season compared with other seasons $(p<0.05)$. Cows performed self-grooming or mutualgrooming, through licking and rubbing. A previous study suggested that if a cow has glossy hair and soft skin it was healthy (Han et al., 2004).

Tail rubbing was significantly higher in cows housed on the sawdust treatment during summer. Tail rubbing was higher in cows on the sawdust, rice husk and wood shaving litters during summer compared with other season $(\mathrm{p}>0.05)$.

As stated above, the grooming behavior of cattle varied according to litter and seasons. Based on the results of this study, cows were judged to be growing more healthily when housed on the sawdust and wood shaving litter compared with the rice husk litter. With consideration of the cows' comfort and the farms' budget, sawdust or wood shaving litter during spring and summer and rice husk litter during winter were regarded as the most beneficial to the lying and licking behavior of Hanwoo beef cattle. Rice husk is usually cheaper during harvest compared with other seasons. Therefore, changing litter choice according to the seasons can be beneficial and cost effective for rearing Hanwoo beef cattle.

\section{ACKNOWLEDGEMENTS}

This study was supported by 2014 Research Grant from Kangwon National University (No. 120140221).

\section{REFERENCES}

AOAC. 1995 Official methods of analysis. $17^{\text {th }} \mathrm{ed}$. Association of official agricultural chemists. Gaithersberg, MD, USA.

Fregonesi, J. A., D. M. Veira, M. A. G. von Keyserlingk and D. M. Weary 2007 Effects of bedding quality on lying behavior of dairy cows. J. Dairy Sci., 90: 5468-5472

Gottardo, F., G. Cozzi, S. Preciso and L. Ravarotto 2003 Effect of type of floor and space at the manger on growth performance and feeding behavior of beef cattle. J. Italy Anim. Sci., 2: $322-324$

Grossi, G., A. Perski, M. Ekstedt, T. Johanson, M. Lindstrom and K. Holm 2005 The morning salivary cortisol response in Burnout. J. Psyc. Res., 59(2): 103-111

Gygax, L., C. Mayer, W. H. Schulze, K. Friedli and B.Wechsler 2007 On-farm assessment of the welfare of finishing bulls kept in housing systems with different floor quality. J. Anim. Welfare Sci., 16: 205-208

Haley, D. B., A. M. Passille and J. Rushen 2001 Assessing cow comfort: Effects of two floor types and two tie stall designs on the behavior of lactating dairy cows. J. Anim. Behavior Sci., 71: 105-117

Han, J. H., D. J. Kim, J. H. Jeon, H. H. Jang, J. M. Koo, E. J. Kin, H. J. Lee and S. C. Yeon 2004 Behavioral characteristics of Hanwoo (Bos Taurus Coreanae) cows and their calves. J. Anim. Sci. \& Tech., 46(1): 115-112

Hanwoo Research 2005 Hanwoo. Dawon Press, Seoul (South Korea)., pp. 259-265

Havlin J. M. and P. H. Robinson 2015. Intake, milk production and heat stress of dairy cows fed a citrus extract during summer heat. Anim. Feed Sci. Tech., 28: 23-32 
Irps, H. 1987 The influence of the floor on the behavior and lameness of beef bulls. Martinus Nijhoff Dordrecht Press, Amsterdam (Netherlands), pp. 73-86

Ishi, M. 1986 Behavior of Cow. livestock Press, Tokyo (Japan), pp. 116

Kim, D. G. and D. U. Jung 2004 Effect of pen floor condition resulted from housing orientation on the performance of finishing Hanwoo steers. J. Anim. Environmental Sci., 10: 37-46

Lee, J. H. 2014 How to management deck change of season deck broiler house in Korea. Korea Environment Inst. Press, Seoul (South Korea), 549: 50-43

Legrand, A. L., M. A. G. Keyserlingk and D. M. Weary 2009 Preference and usage of pasture versus free-stall housing by lactating dairy cattle. J. Dairy Sci., 92: 3651-3658

Mader, T. L., M. S. Davis and T. B. Brandl 2006 Environmental factors influencing heat stress in feedlot cattle. Nebraska Univ. Press, Lincoln(USA), pp. 712-719

Martin, P. and P. Bateson 2007 Measuring behavior; an introductory guide. Cambridge Uni Press, Cambridge (England), pp. $48-61$

Metz, J. H. M., H. K. Wierenga, FF. J. Grommers and H. G. Bure 1986 Het welzijn van rundvee in bedriffsverband: Rapport van de Werkgroep Welzijn Rundvee. Min. van Landb En Visserij, Press, Rome (Italy), p. 104

Mimura, G. et al. 1997 Animal behavior. Kunkuk Univ. press, Seoul (South Korea), pp. 217-227

NIAS (National Institute of Animal Science) 2007. Korean feeding standard for Hanwoo. Rural Development
Administration Press, Jeonju (South Korea), pp. 38-41

Nonaka I., N. Takusari, K. Tajima, T. Suzuki, K. Higuchi and M. Kurihara 2008. Effects of high environmental temperatures on physiological and nutritional status ofprepubertal Holstein heifers. Livestock Sci., 113: 14-23

Phillips, P. A., D. Fraser and B. Pawluczuk 2000 Floor temperature preference of sows at farrowing. J. Anim. Behavior Sci., 67: $59-65$

Reich, L. J., D. M.Weary, D. M. Veira and M. A. G. von Keyserlingk 2010 Effects of sawdust bedding dry matter on lying behavior of dairy cows: A dose-dependent response. J. Dairy Sci., 93 $1561-1565$

SAS Institute 2003 SAS User's Guide. Version 9.1. SAS Institute Inc., Cary, NC, USA.

Sato, S., S. Sako and A. Maeda 1991 Social licking patterns in cattle (Bos taurus): Influence of environmental and social factors. Applied Anim.Behaviour Sci., 32: 3-12

Song, Y. H. 1996 Understand of farm animal behavior. Egong world Press, Seoul (South Korea), pp. 158-188

Song, Y. H., J. H. Cho, W. J. Jang, Y. W. Kim, S. G. Li and J. J. Ha 2007 Maintenance and social behavior characteristics of Hanwoo steers by season. Anim. Res. Sci., 18: 68-71

Spiger, I. M., S. Trivett and D. Fraser 1972 Grooming behavior and competitive dominance in the albino rat. J. Comparative \& Phys., 78: 409-411

Rook, A. J. F. and P. C. Thomas 1983 Nutritional physiology of farm animals. Longman Press, London (England), pp. 639669 